\title{
Conversational humour in a Nigerian radio news programme: A case study of Lati inu aka aka Biodun/Kayode
}

\author{
Blessing T. Inya \\ Federal University Oye-Ekiti \\ blessing.inya@,fuoye.edu.ng
}

\section{Onwu Inya}

Federal University of Technology, Akure

dodinya@gmail.com

\begin{abstract}
This paper investigates the Generic Structure Potential (GSP) of Lati inu aka aka Biodun/Kayode (LIABK), a Nigerian secondary gatekeeping radio news programme, with the aim of indicating the stages of the genre where conversational humour typically occurs, and then it analyses humour types in the data through the neo-Gricean concept of untruthfulness and pragmatic act theory. The data for the study constitute a ten hour audio recording of Lati inu aka aka Biodun/Kayode from two radio stations in Ekiti and Ondo States, South-Western Nigeria. The GSP of LIABK is constituted by five obligatory elements: Opening $(O)$, Advertisement (A), Pre-news Presentation (PnP), News Presentation (NP) and Closing (C). The genre-based expectations for $O, P n P$ and $C$, and then NP are to provide entertainment and information to the listeners respectively. Thus, humour typically occurs in the $O, P n P$, and $C$ stages of the programme, and rarely occurs in NP. Four humour types are indicated: song-as-humour, absurdity, joint fantasising, and speaker-meaning-telic humour respectively. While song-as-humour resists being neatly categorised as autotelic humour, absurdity and joint fantasising are easily characterised as thus. The pragmatic act analysis reveals the incremental, sequential, and co-constructed nature of the humour types. Furthermore, the pragmemes of entertainment and offering of opinion by the news presenters constitute the affordances or genre-based expectations that constrain the social activities that constitute $L I A B K$. The study contributes to the scholarship on secondary gatekeeping in Nigeria broadcast media, conversational humour, and pragmatics.
\end{abstract}

Keywords: conversational humour; untruthfulness; secondary gatekeeping; GSP; pragmeme, pragmatic act, speaker-meaning, Biodun-Kayode, news. 


\section{Introduction}

Lati inu aka aka Biodun/Kayode (henceforth $L I A B K$ ), the radio news programme that constitute the data for this paper, is an instance of the secondary gatekeeping phenomenon (Ojebuyi \& Ojebode 2012), which is not only emergent in the Nigerian broadcast media, but rapidly becoming pervasive, and yet has not received sufficient scholarly attention in both media and linguistic studies. Ojebuyi \& Ojebode (2012), who, from the perspective of media studies, examined this practice by radio stations in Oyo State, South-western Nigeria, conceptualise secondary gatekeeping as a case "where a news medium selects and broadcasts fragments of the contents of another, primary media" (Ojebuyi \& Ojebode 2012: 62). In other words, secondary gatekeeping occurs when broadcast media, particularly the radio, "monitor[s], select[s] and broadcast[s] some portions of the contents of the print media" (Ojebuyi \& Ojebode 2012: 63). The practice takes the form of reviewing (indicating the headline and providing the gist of the item) news items from daily newspapers. The thrust of Ojebuyi \& Ojebode's work is the investigation of the motive for secondary gatekeeping by the selected radio stations, and the rhetorical strategies deployed in the presentation of the secondary gatekept contents. They found, from in-depth interviews with the editorial personnel of the station, that the motive for the programmes is to satisfy the audience, which would result in an increase of listenership and more profit margin in the market place. With respect to the presentation style, the study reveals that dramatisation, paraphrasing and suspense, translation, and voice modulation and mimicking are the rhetorical strategies deployed by presenters with the goal of stimulating and sustaining listeners' interest. Other conceptualisations of secondary keeping are in relation to online or digital news selection process and border on the idea that traditional gatekeepers seem to be increasingly sharing their status of information controllers with internet user. Singer (2014) notes that the expanded role of internet users as secondary gatekeepers has resulted into "a two-step gatekeeping process, in which initial editorial decisions to make an item part of the news product are followed by user decisions to upgrade or downgrade the visibility of that item for a secondary audience" (Singer 2014: 55).

Ojebuyi \& Ojebode (2012) is relevant to the current effort in two ways. First, the genre investigated therein, namely secondary gate-kept contents in a radio news programme, constitutes the data for our study. As an emergent genre, secondary gatekeeping in broadcast media requires systematic analysis in terms of its constituent parts. This would, among other things, help to indicate the specific stages of the communicative genre where conversational humour is wont to occur and how the presenters shift from the humorous frame to the journalistic frame. This would have the explanatory potential of specifying what cues the presenters to know when to engage in conversational humour and otherwise. Second, the argument that this news review programmes combine humour with the presentation of news contents to sustain listeners' interest, highlights the centrality of humour in the delivery of secondary gate-kept news items in broadcast media in Nigeria. The authors recurrently emphasise the importance of humour as they indicate the different categories of humour types such as jokes, proverbial analogies, metaphorical expressions, voice modulation, and mimicry, which they broadly categorise as rhetorical devices deployed by presenters meant to "attract the listeners to their radio station" (Ojebuyi \& Ojebode 2012: 72). Thus, if humour is fundamental to this pervasive practice in Nigerian broadcast media, it follows that an in-depth study of conversational humour, operationalised as the exchange of humorous contents between the presenters with the intent of amusing listeners and/or commenting on news items in secondary gate-kept news programme is paramount. Furthermore, lacing news contents with humour implies an alternation between non-serious and serious modes/frames of 
communication. The dichotomy between seriousness and non-seriousness is underscored by research in conversational humour.

A thorny theoretical issue with conversational humour $(\mathrm{CH})$ is how it can be ance playful, and yet communicate 'serious' meaning (Dynel 2017). Humour basically presupposes an activity people engage in precisely for the purpose of amusement. However, equating humour with non-seriousness, playfulness, and jocularity and contrasting it with seriousness is the basic conceptualisation of the phenomenon in literature. For instance, Dynel (2017: 84) avers that this conceptualisation "has frequently been taken as a bedrock premise in the conversational analytic approach to humour". However, conceptualising humour as both associated with seriousness and non-seriousness obscures what categorically constitutes this communicative act, especially as humour cannot be characterised both as playful, jocular, non-serious, etc. and then reducible to seriousness or the communication of serious message (Vincent Marrelli 1994; Lockyer \& Pickering 2008; Haugh 2010). The noncategorical nature of humour motivates Dynel's (2017) reliance on the concept of untruthfulness as means to a more fruitful, abstract characterisation of humour in conversations. For Dynel (2017), the concept of untruthfulness provides an independent platform from which to conceptualise the humour vs. seriousness dichotomy, and because it operates at an abstract level, the labelling confusion that have plagued previous studies is avoided. Thus, Dynel (2017) draws from the neo-Gricean concept (un)truthfulness, which is a derivative of the first maxim of Quality, to categorise humour into two broad types, namely "autotelic humour (which resides in opting out of this maxim) and speaker-meaning-telic humour (which communicates truthful or covertly untruthful speaker meaning by means of fulfilment, flouting or violation of this maxim and the other ones as well)" (Dynel 2017: 83). She indicates that theorising the pragmatic mechanism that underlies humour from the perspective of (un)truthfulness accounts for "a full spectrum of humour manifestations without causing any terminological contradictions" (Dynel 2017: 83).

In other words, the humour types analysed in previous research, and the idea that humour can be produced for the sake of amusement and/or for communicating serious meaning are re-categorised on the basis of the (non)fulfilment of the first Quality maxim, amongst other things. One goal of this paper, therefore, is to apply these categories of humour to a data of naturally occurring interactions in $L I A B K$ to see how well they account for instances of $\mathrm{CH}$ in the data. We, on the other hand, indicate that Dynel's (2017) categories may not be able to handle the co-construction of, as well as the social goals and expectations that underscore the production of, $\mathrm{CH}$ in the data. We, therefore, complement Dynel's (2017) theory with that of pragmeme/pragmatic act, introduced and developed by Mey (2001) and Capone (2005) respectively.

Overall, therefore, this paper intends to, first, characterise the Generic Structure Potential (Halliday \& Hasan 1985; Inya 2012) of $L I A B K$ as an instance of secondary gatekeeping in broadcast media by identifying the obligatory, optional, and iterative elements of the discourse, by indicating the precise location of the interaction where humour typically occurs, and by examining how the presenters move from the humorous/non-serious frame to the serious frame and vice versa. The second aim of the paper is to analyse the pragmatic mechanism that underpin the humour types identified through the concept of untruthfulness, and the social goals that characterise this emerging practice of secondary gatekeeping through pragmeme. The overall implication of pursuing these objectives would be an explicit characterisation of the constitutive parts of $L I A B K$ with particular interest on the humorous part, which has been reported to be key in both understanding and appreciating the genre of secondary gatekeeping in Nigerian broadcast media. Furthermore, drawing on the theories of neo-Gricean and social pragmatics, we provide insight into the socio-cognitive dimensions of the communicative event, with specific focus on both the intentions of the presenters for 
encrusting serious news contents with humour and the communicative functions of this pragmatic act.

\section{Theoretical foundation}

The theoretical foundation of this paper is based on the following theories: Generic Structure Potential (GSP), neo-Gricean untruthfulness, and pragmatic act, and they are reviewed in turn below.

\subsection{Generic Structure Potential}

Generic Structure Potential (henceforth, GSP) is a schematic construct put forth by Hasan in Halliday \& Hasan (1985; see also Hasan 2014: 9-11) to explain the possible text structure of a given genre or register family. In order to theorise about GSP, Hasan introduces the concept of Contextual Configuration, which specifies the values that realise the three variables of the context of situation (field, tenor, and mode of discourse), and on the basis of which statements about the appropriate text structure of a given genre are made. Contextual Configuration determines the elements that must occur in a text, the ones that may occur, the ones that are recursive (that is, able to occur more than once), and their possible arrangements in the overall structure of a text. Hasan (2014) argues that a GSP consists of "a configuration of functional elements whose mutual relations are calibrated in such a way as to allow its use to describe the structure of not only a specific text type but also a range of other related text types" (Hasan 2014: 9). In other words, a particular GSP specifies the structural possibilities for a particular genre - elements which are obligatory, optional, recursive, and in what possible orderings. The GSP of a genre, therefore, makes the characterisation of texts possible by locating them within a specific genre if their structures are compatible with one of the possibilities specified by the GSP. Thus, GSP "represents the preferred textual organisation for texts in such a genre and this preference is hinged on the social/communicative purpose the genre sets out to achieve" (Inya 2012: 76).

GSP reveals the constitutive parts of a particular genre in terms of its obligatory, optional and recursive elements, which are reflexive of the situational context of the interaction that specifies the restrictions and affordances (Mey 2001) of the communicative event. This makes it relevant to the first aim of this paper. The paper hinges the GSP of LIABK, especially the elements that warrant the exchange of conversational humour on an even more robust concept of context, namely pragmeme, which shall be reviewed shortly. We now turn to the concept of untruthfulness as articulated by Dynel (2017).

\subsection{Dynel's untruthfulness theory}

The thrust of Dynel's (2017) study is a call for an alternative conceptualisation of humour with respect to whether it is performed for amusement and/or to express speaker meaning. Her theory is based on the notion of (un)truthfulness predicated on diverse responses to Grice's first Quality maxim ("Do not say what you believe to be false"; Grice 1989: 27), i.e. whether it is observed, opted out from, flouted, or violated (Grice 1989). Through this notion, Dynel (2017) indicates the complex relationship between conversational humour and (un)truthfulness. More precisely, she avers that the concepts of truthfulness, covert untruthfulness, overt untruthfulness, and overt autotelic untruthfulness can account for humour. On the basis of these shades of (un)truthfulness, she categorises humour into autotelic humour, which is purely for the sake of amusement, and speaker-meaning-telic 
humour, which is imbued with speaker meaning ${ }^{1}$ in Grice's sense, and thus has implications beyond the humorous frame.

According to Dynel (2017), autotelic humour involves overt autotelic untruthfulness, and is based on opting out of the first Quality maxim, which is overt for the hearer to notice. Thus, it is neither a violation, which would invite deception, nor a flout, which would invite an implicature. She avers that

[t]he intrinsic characteristic of autotelic humour is that it does not carry any speaker meaning in the form of what is said or implicature, even though producing it, the speaker may have (whether or not conscious) communicative goals next to inviting humorous reactions.

(Dynel 2017: 91.)

We argue that although autotelic humour may not communicate speaker meaning, it may be used for pragmatic acting. Furthermore, with respect to humour, Dynel (2017) is careful to distinguish between speaker intended meaning in terms of what is said or implicated, and socio-pragmatic goals, which she calls super-goals. She argues that "[t]hese super-goals coincide with the functions of humour addressed in socio-psychological and socio-pragmatic studies, such as exerting interpersonal effects by promoting solidarity or boosting one's likeability" (Dynel 2017: 87). Although she makes this distinction, she focuses only on the presence or otherwise of speaker meaning, and does not systematically analyse the instances of these super-goals in her data. Thus, we evince that these super goals can be fruitfully accounted for within pragmeme/pragmatic act theory (Mey 2001; 2016).

Dynel (2017) defines speaker-meaning-telic humour as "utterances that have a capacity to amuse and simultaneously communicate speaker-meaning, and thus truthful or covertly untruthful meanings, which are not part of the humorous frame" (Dynel 2017: 95). However, the continuum of speaker intention in speaker-meaning-telic humour is between transparency, ambivalence, and purposefully covert. Thus, the context of interaction, which Mey (2016) describes as including "the respective status of the participants, their prior history and connections, the ambiance (formal vs. colloquial), the mode of delivery (such as tone of voice), facial and other gestures (e.g. presence of a 'wink')" (Mey 2016: 136), must be taken into consideration in order to correctly or near-correctly identify the speaker's true intentions. Furthermore, according to Dynel (2017), the overt untruthfulness that typically characterises speaker-meaning-telic humour is based on flouting the maxim of Quality, which generates implicatures, and this typically involves such figures as metaphor, hyperbole, irony, etc. In other words, speaker-meaning-telic humour, arising through overt untruthfulness, is typically associated with quality-based figures, namely metaphor, hyperbole, irony, meiosis, proverbs, sung-tale metaphors, etc. The point is that these phenomena, if creatively deployed, may invite amusement; however, they are principally connected with the communication of speaker meaning. Their overt untruthfulness resides precisely in the fact that they flout the Quality-based maxim. As such, these quality-based figures can give off truthful meanings at the level of implicature.

The basic point of Dynel's (2017) characterisation of humour is that a communicative act is purely humorous to the extent that it is overtly autotelically untrue. In other words, the truthfulness of what is being said is suspended or irrelevant (cf. Raskin \& Attardo 1994; Wilson \& Sperber 2000). Thus, the speaker in doing autotelic humour says what $\mathrm{s} /$ he believes to be untrue, and the hearer accommodates such untruthfulness, and therefore, the speaker opts out of the maxim of Quality. Therefore, the concept of autotelic untruthfulness should be able to account for the internal pragmatic mechanisms of a diversified class of humour, but not necessarily their co-construction, nor the communicative genre that constrains and constitutes them. In other words, the concept of untruthfulness may suffice to delineate the internal, abstract, cognitive pragmatic mechanisms that underpin different humour types, but 
does not strictly inform on the expectations and affordances that warrant their emergence in a specific communicative genre. Therefore, the category of autotelic humour is applied to our data to analyse communicative exchanges that "fly in the face of objectively verifiable truth" (Dynel 2017: 91) that do or do not carry any speaker meaning. The category of speakermeaning-telic humour is also applied to the data. However, with respect to the genre-based expectations and affordances that underpin interaction in the data, the concepts of GSP and pragmatic act provide clearer insights, and are thus adopted to do further analysis.

\subsection{Mey's pragmeme/pragmatic act theory}

Pragmatic act theory, a socio-cultural interactional view on pragmatics, was proposed by Mey (2001). The theory is based on the premise that speech act theory lacks an action theory, which means that the seeming action in speech act stems from the individual's intentions and the strategies s/he employs in achieving them. As such, pragmatic act theory promotes "the priority of socio-cultural and societal factors in meaning construction and comprehension" (Kecskes 2010: 1) and focuses heavily "on the interactional situation in which both speakers and hearers realise their aims" (Mey 2009: 751). The thrust of the theory is simply that the utterance or speech act is only one factor, which must work hand in hand with other situational/contextual factors for meaning realisation or for the performance of a pragmatic act. Consequently, Mey (2001) argues that "there are no speech acts but only situated speech acts or instantiated pragmatic acts" (Mey 2001: 218); as such the emphasis is on identifying a general situation prototype, which is called a pragmeme, and can be realised through individual pragmatic acts (Mey 2001: 221).

According to Capone (2005), "[a] pragmeme is a situated speech act in which the rules of language and of society synergise in determining meaning, intended as a socially recognised object sensitive to social expectations about the situation in which the utterance to be interpreted is embedded" (Capone 2005: 1357). In other words, the pragmeme "is the situation of acting which both provides the possibilities and creates the restrictions that are inherent in the well-formed act of speaking" (Mey 2016: 137). Capone (2005: 1357) further indicates that the pragmeme requires three types of embedding:

- The embedding of an utterance in a context of use, with an aim to determine the referential anchors that complete the propositional form of the utterance.

- The embedding in rules that systematically transform whatever gets said in a context into whatever is meant there, in conformity with the social constraints and rules bearing on the utterance in question.

- The embedding in the co-text, whose features are transferred onto the utterance by eliminating semantic or otherwise interpretative ambiguities and enriching further its (range of) interpretations, by making them more specific.

This requisite embedding of an utterance in the co-text and context is largely an interpretative process that enriches the propositional form of such utterance and assigns a particular contextual configuration that will make the meaning of the utterance more specific, thereby discarding other alternative interpretations that may not be inferable from such a situational configuration. It is a norm of utterance interpretation that relies on the social context of the utterance and other co-textual elements. Interestingly, Capone is to later reveal that "a pragmeme need[s] not be an utterance and sometimes may be equivalent to long, structured, and completed units" (Capone 2016: xvii). It is this sense of longer interactional pieces of conversational humour that pragmeme is understood in this paper. For instance, that the pragmeme of entertainment, which is realised through the creative use of humour, can be 
characterised by examining sequences of joint fantasising or absurdity across turns. In other words, our characterising of pragmeme may be based on a single utterance or an entire interactional piece.

Culpeper \& Haugh (2014) also engage the question of pragmatic acts. However, they depart from Mey's (2001) conceptualisation as they adopt a schema-theoretic approach and attempt "to formalise the[se] conditions or affordances" that underpin pragmatic acts (cf. Culpeper \& Haugh 2014: 182-185). Culpeper \& Haugh's (2014: 185) idea of pragmatic acts as dependent "not only on whatever plan or agenda the speaker may have in mind, but, crucially, on the responses of the other participant(s) and the broader activity or event in which they occur" represents our understanding of the concept in this paper. Culpeper \& Haugh (2014) point out three implications of this understanding: 1) pragmatic acts develop both incrementally and sequentially within and across turns; 2) pragmatic acts are coconstructed by both speaker and recipients, and thus, not the a product of the speaker only; and 3) pragmatic acts are constrained by and constitutive of the broader activity types (or communicative genres) that frame them. In other words, the concepts of incrementality, sequentiality, co-construction and genre are fundamental to understanding pragmatic acts. Thus, with respect to our data, we argue that the performance and appreciation of conversational humour types are made more salient as the presenters incrementally coconstruct humorous turns. The turns rely on the sequential context of prior and subsequent turns and an understanding of/adherence to expectations or affordances of the specific stage of the news review programme. The overall genre, namely secondary gatekeeping in broadcast media, equally constrains the performance of humour in the data.

\section{Methodology}

The data for the study are based on personal recordings of $L I A B K$, a Yoruba newspaper review programme presented by Biodun Ilori and Kayode Falegan on Ekiti State Radio FM 91.5 and Adaba 88.9 FM Akure between 8:30 to 9:00 am on 91.5 FM and 9:00 to 9:30 on 88.9 FM every weekday. The recordings, which totalled ten hours, were done between August and October 2017. This particular programme was chosen because it is popular in the South-west states of Ekiti and Ondo, where the researchers reside. As indicated above, the newspaper review programme is an instance of secondary gatekeeping, which implies that it reviews news items selected from national dailies and online news sites such as The Punch, The Guardian. Premium Times, Wazobia Reporter, The Herald, Vanguard, Daily Post. The recordings were listened to with the goals of 1) identifying the GSP of the news programme and 2) analysing selected instances of conversational humour, categorised either as autotelic or speaker-meaning-telic, and the pragmeme/pragmatic acts that constrain/constitute the overall news review programme. $L I A B K$ is constituted by dialogues by the two presenters, who are the only participants. The turn-taking rules range from random, at the opening, closing and pre-news presentation stages of the programme, and systematic during the news presentation stage, at which stage the presenters take turns at reviewing the news items. The dichotomy/alternation between random and systematic turn-taking styles reflects the fact the opening/closing/pre-news presentation stages are unscripted and, therefore, spontaneous, while the presentation stage is scripted and thus requires a systematic alternation of turns at reviewing news items by presenters. As the GSP analysis will show, the programme has a fairly stable, predictable pattern.

Because the data is originally in Yoruba, specific data that are used to illustrate theoretical points were both paraphrastically and literally translated into English by the first author, who is a native speaker of the Yoruba language and a competent speaker of the 
English language. The initial letters of the presenters' names are used to represent them in the transcript; as such, K stands for Kayode and B for Biodun. The interactions were transcribed using Jefferson's (2004) CA notations to account for the conversational nuances in the data. The goals of the paper is to characterise the GSP of LIABK and to analyse humour types in the data in terms of their internal pragmatic mechanism, their co-construction and the genrebased expectations or affordances that constrain or constitute them. Therefore, the data analysis is a discourse pragmatic and qualitative-based one, which examines the GSP, instances of the humour types and the pragmatic acts therein.

\section{GSP of Lati Inu Aka aka Biodun/Kayode}

The first aim of the paper is to establish the genre status of the newspaper review programme $L I A B K$ as an instance of secondary gatekeeping in Nigerian broadcast media, and with the goal of indicating constituent parts of the programme within which conversational humour is afforded. The representation below is the GSP of $L I A B K$ :

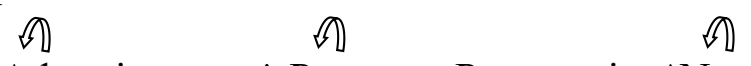

[Opening] $]^{\wedge}$ Advertisement.^ Pre-news Presentation ${ }^{\wedge}$ News Presentation ${ }^{\wedge}[$ Closing $]$

The GSP of LIABK is constituted by the following elements: the Opening (O), Advertisements (ADV), Pre-news Presentation (PnP), News Presentation (NP), and Closing (C). All the elements are obligatory in the sense that they all occur in a typical instance of the programme. However, the core obligatory elements that indicate the field of discourse, the social action/activity that is definitive of the genre are the Opening, Pre-news Presentation, News Presentation, and Closing. Additionally, the square brackets [] that enclose [Opening/Closing] restricts the occurrence of the elements at their respective positions, namely at the beginning and ending of the programme. The curved arrow shows recursiveness, which implies that the elements of Advertisement, Pre-news Presentation, and News Presentation occur more than once in a typical programme. The (.) between Advertisement and Pre-news Presentation and News Presentation means that more than one option in sequence is possible. In other words, Advertisement can occur after Pre-news Presentation and News Presentation as well as before. Lastly, the caret $\left(^{\wedge}\right)$ signs show the sequential progression of the news programme.

The Opening stage (cf. examples 1-2) is further constituted by salutations, appreciations, prayers, introductions, and general banter. Opening usually runs for the first two to three minutes of the programme. This stage of the interaction is characterised by a random and flexible turn-taking rule with either of the presenters speaking first. Thus, the stage is indexed by frequent overlaps, interruptions, and co-constructed turns (cf. lines 8-14 of example 1). The stage is equally characterised by an abundance of laughter particles (cf. lines 15-22 of example 2; see also Shaw et al. 2013). The laughter particles together with other indices of humour point to the frequent occurrence of conversational humour in this stage of the programme. The Closing, constituted by giving credits, announcements, non-news stories, and signing out, is similar to the Opening in a number of regards: flexible turn-taking resulting in overlaps, interruptions, and co-constructed turns, and richness of laughter particles, which potentially signal the presence of humour.

The Pre-news presentation stage (cf. example 3) is characterised by conversational exchanges that foreshadow the news items to be presented, and these exchanges are typically formulated either as recontextualisation of the intended news item (cf. Example 3) or as gist. Through recontextualisation, a forthcoming news item is reframed into a non-serious and most times playful frame, with the intention of eliciting laughter or expressing opinions by 
the presenters. Specifically, the presenters take up the roles of the news actors and attribute the verbal, material, or mental aspects of the news events to themselves. The end of the recontextualisation phase is signalled through a metapragmatic comment or a retractive statement formulated thus: Emi ko ni mo so be e o 'I am not the person who said that' (cf. lines 19-24 of example 3). With this statement, the news item is then attributed to the actual news actors and the presenters proceed to read the news item (cf. lines 21, 25-26 of example 3 ). The gist option of the Pre-news Presentation stage takes the form of stating the headline or highlighting a specific dimension of the news event, which is typically followed by explicit markers of bias or presenter opinion - Oga o; Ki Olorun o saanu fun wa 'That's very serious; May God have mercy on us'. These opinion markers tend to evaluatively frame the forthcoming news item for the listener in the light of the presenters' opinion. The following formulation or its variants Je ki $n$ lo mu iroyin naa wa 'Let me bring forth the news' (cf. line 25 of example 3) simultaneously mark the end of the Pre-news Presentation stage and begin the News Presentation stage. News Presentation is constituted by the reading of the secondary gatekept news items and it is marked by a fairly lengthy, uninterrupted, monologic turn presented by one of the presenters, who is selected at the beginning of the Pre-news Presentation through a call and response strategy (cf. lines 1-4 of example 3). Humour rarely occurs at this stage, and the presenters end this stage by referring listeners to the newspaper the item was selected from.

The foregoing implicates two dichotomies: unscripted, spontaneous conversational exchanges vs. scripted, monologic presentation of news items, and then non-serious, playful, jocular exchanges vs. the serious, "information-conveying" (Raskin 1985: 59) and "factconveying" (Raskin \& Attardo 1994: 32) mode of communication. The first dichotomy reflects the genre-based expectations that underscore the GSP of LIABK and, consequently, frame the mode of interaction at the discursive level, which implicates the second layer of dichotomy. Thus, the Opening, Closing, and Pre-news Presentations stages are typically unscripted spontaneous, and therefore, cue the presenters that non-serious, playful, and humour-based exchanges are expected at this points in the programme. Conversely, the News Presentation stage is typically scripted (cf. ka iroyin 'read the news', which implies its scriptedness; see lines 25-26 of example 3) and conveys serious, factual information. Hence, the likelihood of humour is reduced, as the expectations of this stage does not warrant doing humour. Essentially, the dichotomies above mirror the distinction between an everyday, spontaneous, conversational genre and a journalistic, mediated communicative genre, and coalescing, blending these disparate genres is the hallmark of $L I A B K$, and by extension of the Yoruba-based secondary gatekept news review programmes in broadcast media. This conclusion finds support in the study by Ojebuyi \& Ojebode (2012). Thus, secondary gatekeeping is a hybrid genre, which straddles the genres of spontaneous conversation that warrants the occurrence of conversational humour and journalistic genre which focuses on conveying information about factual happenings. We now turn to the analysis of humour types in the data.

\section{Humour types in Lati Inu Aka aka Biodun/Kayode}

\subsection{Song-as-humour}

As a humour category, songs are creatively deployed by the presenters of the programme, mostly with the goal of amusing listeners. This humour category typically occurs at the Opening, Pre-news Presentation, and Closing stages of the programme. Example 1 is an instance of singing and it occurred at the Opening stage of the programme of $8^{\text {th }}$ August, 
2017. The occurrence of humour in the opening is consistent with the genre-based expectation for this stage of the interaction.

[The transcript is from $8^{\text {th }}$ of August 2017, and the interaction revolves around the birth of a new baby to Kayode, one of the presenters. The interaction is a song that felicitates with the parent of a new baby, especially its mother.]

\section{Example 1}

1. K: The mother of the child $\uparrow$

2. B: No:: I won't greet the mother. hhh £Father of the child

3. K: [Congra-

4. B: $£[$ Congratulation $(0.2)$

5. B: HehHeh

6. (the presenters mimic instrumental sounds)

7. B : Father of the child, I greet you $\downarrow$ (.)

8. $\mathrm{K}:=$ Congratulations $\uparrow$

9. $\mathrm{B}:=$ Congratulations $\uparrow$

10. B: $\rightarrow £$ Kayode’s hands are in the water “o". Congrat[ulations $\uparrow(0.2)$

11. K: $\rightarrow \quad$ [How will I read out the news then? (0.2)

12. B: $\rightarrow$.hhh £Oku owolomi [o Congratulations (Cultural greeting for parents of newborn. It literally means well done for having your hands in the water)

13. K: [HehHehHehHeh

14. B: HehHehHehHeh[HehHEh

This sequence begins with a song that expresses gratitude to God for the safe delivery of Kayode's child. The song narrates the experience of being pregnant, delivering safely and the felicitations and celebrations that accompany such an experience. Each line of the song is punctuated with the expression $K u$ ayo, kuewu, which roughly means 'congratulations'. However, Biodun begins to creatively invent new lines for the song, which initially are seen as unexpected, and then outrightly humorous. The initial unexpected stage is captured in lines 1-5, while lines 7 to 15 reflect the humorous part of the exchange. In line 1, Kayode sings the preferred turn for this stage of the song, which salutes the mother of the child, but Biodun disagrees and congratulates the father of the child instead (lines 2, 4). B's felicitation is conveyed with a smiling voice, and this elicits laughter from B. However, the laughter in line 5 is not in response to any autotelic (untruthful) humorous design, because the turns so far are truthful expressions of gratitude and felicitations. Thus, the laughter in line 5 is an indication of the enjoyment of the joint activity both presenters are engaged in, namely singing, particularly the incongruous contribution made by B in line 2. Chovanec (2017: 43) classifies this type of laughter as non-humorous and argues that it accompanies the experiential aspects of interlocutors' on-going interaction. He evinces that non-humorous laughter could manifest as a response to a successful accomplishment of a joint physical activity, or as a way to appreciate new, unexpected, incongruous experiences. In the case of its instance in line 5, B's refusal to felicitate with the mother of the new-born, and choosing rather to congratulate the father is refreshing, spontaneous, and incongruous to the expectations of $\mathrm{K}$, hence the laughter. The instance of song-as-humour analysed above resists being neatly categorised as autotelic humour because it covers speaker meaning in terms of truthful what is said. However, humour emerges when the presenters creatively tweak the song, which renders it incongruous. 


\subsection{Absurdity}

Autotelic humour clearly begins to emerge when B makes an overtly untruthful statement about K's hands being in water (example 1, line 10), and $\mathrm{K}$ response implicates the difficulty of reading the news off the script if his hands are indeed in water. The autotelic humorous nature of lines 10 and 11 is anchored on two issues: first, the fact that it involves overt autotelic untruthfulness, which is based on opting out of the first Quality based maxim (Dynel 2017), and this is plain, overt for the hearer to notice. Thus, it is neither a violation, which would invite deception, nor a flout, which would invite an implicature. The intention of $\mathrm{B}$ in line 10 is to amuse $\mathrm{K}$ and, by extension, those who listen to the radio programme. The second issue is K's response (line 11) which communicates a truthful meaning, namely if his hands are in water, how is he going to hold the newspaper in order to read the news, which implicates the absurdity of B's turn. This absurdity is precisely the point of line 10 and, as Dynel (2017: 93) avers, absurdity "is one of the common means of producing autotelic humour", precisely because it "rests on notions that fly in the face of reality, common sense or logic". Furthermore, B retorts (line 12) by invoking a cultural script, one which is activated when felicitating with the parents of a new baby. The expression in line 12 literally means 'well done for having your hands in water', which is a metonymy for taking care of a baby (because caring for a baby involves a plethora of water-based activities: bathing, washing, cleaning, etc.). Although the metonymic expression in line 12 communicates truthful implicature about acknowledging the effort and activities that go into caring for a baby, its use in the context of this example presents an interesting case. For instance, it could be the case that $\mathrm{B}$ intends to communicate truthfully the implicature of felicitating with $\mathrm{K}$ on having a new baby, in which case the autotelic nature of line 12 would be called into question. It could also be the case that B intends for his turn to be treated humorously. The ambivalent nature of line 12 could be resolved by recourse to the sequential context of the interaction, precisely the preceding and succeeding turns. First, line 10 is a humorous allusion to line 12, and line 10 has been established as being overtly untruthful and absurd. Thus, the absurdity of line 10 seems to influence the way line 12 is received. Second, the foregoing argument is also predicated on the response that $\mathrm{K}$ gives to line 12: laughter (line 13), which overlaps with B's turn, and is further overlapped by B's laughter (line 14), which serves as a reinforcement (Holt 2016: 91) of the humorous design of line 12. Consequently, line 13 seems to orient to the autotelic side of line 12 rather than its speaker-meaning-telic side. For instance, within a CA analysis of humour, or more precisely of laughter (cf. Sacks, 1992; Glenn 2003; Holt 2016), the design of line 12 displays sequential ambiguity (Sacks 1992: 672), because the recipient or hearer is provided with the options of either responding with the usual sequential implication (Holt 2016: 90) of appreciating the felicitation implicit in line 12, or aligning with the humorous intention through laughter (Glenn 2003; Holt 2016). In the case of the exchange above, $\mathrm{K}$ aligns to the humorous 'packaging' (Holt 2016: 90) of line 12 with the four loud beats, which are reinforced by B's overlapping laughter.

\subsection{Joint fantasizing}

Lines 15-27 begin another dimension of autotelic humour, precisely joint fantasising (Kotthoff 2006; Chovanec 2012). The goal of this sequence is clearly to elicit laughter, and to demonstrate which of the presenters would out-do the other in this exercise of absurdity (Norrick 1993):

\section{Example 2}

15. B: HehHehHehHeh[HehHEh

16. $\mathrm{K}$ : [Boidun is someone who can get one into trouble= 
17. $\mathrm{B}:=$ HehHehHehHehHeh=

18. K: Congr(h)atulation=

19. $\mathrm{B}:=$ HehHehHehHehHeh

20. $\mathrm{K}$ : $£$ His in-law died, and we didn’t sing o Congra(h)tulation $=$

21. B: = Hehhehheh That's a dead body, it has gone to rest

22. K: B Hehhehhehheh

23. $\mathrm{B}:=$ This is a newborn baby who has just arrived $o$. Congratulations. Who knows if it is my wife's mother who re-incarnated in your home $o$. Congratulations.

24. K: Your wife's mother was very dark. Congratulations.

25. B: Is your baby light-skinned?

26. K: The child we have just given birth to is an albino [Congratulations Hehhehhehheh.

27. B: ALBINO $\uparrow$ I doubt if you own the child [then $o$

28. K: It doesn't concern you $o$, there is albino in our [lineage

The characteristics of joint fantasising, besides the fact that it hardly conveys any speaker meaning (Dynel 2017: 93), include the co-construction of absurd or even impossible scenarios or narratives (Stallone \& Haugh 2017), which are based on overt, joint pretence (Clark \& Van Der Wege 2001; Dynel 2017), and are contributed to on an incremental bases (Kotthoff 1999: 130), either by emulating the format of a previous contribution (Goodwin \& Goodwin 1987) or attempting to outperform a previous contribution, and they serve various interpersonal functions ranging from bonding, solidarity, identity work, entertainment, etc. (Chovanec 2012; Stallone \& Haugh 2017). The first central issue observed in lines 15-28 is the fact that most of the contributions are overtly untruthful, contributed with the intention of generating a humorous effect. On the other hand, truthful contributions that occur violate the maxim of relevance, bordering on the absurd. In line 15, K calls B alakoba (lit. 'an individual who gets someone into trouble'), a case of mock insult, and outside this playful frame, the name calling could come at a cost. However, B responds with several beats of laughter, which signal that he takes the rather critical comment as a joke. $\mathrm{K}$ cuts in again with a truthful, but irrelevant information about the death of B's mother-in-law, and the fact that the occasion did not necessitate a song (just like the birth of his son is being celebrated; line 19). Line 19 is another instance of jocular mockery, which is conceptualised as "(non)verbal acts whereby the speaker somehow diminishes something of relevance to self, other, or a thirdparty who is not co-present, but does so in a non-serious or jocular frame" (Haugh 2010: 2108). Interestingly, B is quick to point out, amidst laughter, that his mother-in-law is indeed dead and gone, and could not be bothered whether or not a song was sung for her (line 20). In line 22, B states that K's new baby, who is being celebrated, is an incarnate of his dead mother-in-law, and $\mathrm{K}$ responds in lines 23 and 25 that B's mother-in-law was dark in complexion, while his son is fair-skinned, thus refuting the incarnatory claim of B in line 22 . $\mathrm{B}$ takes the information that K's new baby is fair-skinned as a surprise, which is indicated by the high pitch of his response (line 26), and goes on to state that $\mathrm{K}$ is not likely to be the father of the new baby, which implies that his wife may have been unfaithful. The remaining part of this interaction (not represented here) dwells on the possibility of K's wife's affair with their Albino neighbour.

The following theoretically interesting issues are revealed from the brief analysis above, apart from the point that the interaction is largely autotelic in nature. Firstly, the fantasy that is jointly being constructed by the interlocutors accommodates issues that should be taken seriously. For instance, the death of one's mother-in-law is not a trivial matter, especially within the African socio-cultural context, and should not be the subject of a joke. Equally, implying that one's wife is unfaithful as B insinuates about K's wife could have serious 
repercussions. However, in this sequence of joint pretence or overt autotelic untruthfulness (Dynel 2017), nothing seems to be particularly sacred or off limits. Furthermore, the jocular nature of the interaction is signalled by the abundance of laughter particles (lines 20-21). Secondly, succeeding contributions seem to fly in the face of sanity and morality in an incremental manner. From B insisting that he would rather felicitate with the father of the new baby rather than the mother (line 1) to his implying that $\mathrm{K}$ is not the true father of the new baby shows the escalating dimension of this flight of fantasy (Dynel 2011). As a matter of fact, $\mathrm{K}$ concedes victory to $\mathrm{B}$ towards the end of the sequence of interaction, when he himself seems to suggest that the new baby resembles one of his neighbours who patronises his wife's petty shop very often. Consequently, B seems to emerge as the winner of the 'competition', and comes across as the more imaginative, creative, and funny of the duo. This element of 'one-upmanship' centrally characterises joint fantasising (Stallone \& Haugh 2017). Finally, the fantasy session carries interpersonal and relational implication for the presenters in terms of bonding and solidarity. It also provides entertainment for the listeners of the radio news programme, apart from the fact that information is to be gained from the news reports.

\subsection{Speaker-meaning-telic humour}

As stated above, this category of humour includes utterances that are imbued with truthful speaker meaning which could be at the level of what is said, or at the level of implicature, which results from flouting the first Quality maxim, which is tantamount to being overtly untruthful. In example 3, having begun with their characteristic opening sequence (lines 1-4), namely a sort of call and response, which is designed to create a feeling of conversation and select the next speaker to present the news item, $\mathrm{K}$ indicates that he is happy about the installation of new kings in Ibadan, Oyo State (lines 5, 7). There is an elapsed time (0.2) between K's assertion of his happiness and B's response, which conveys a pretend surprise at K's assertion. The pause and the surprise in B's response rendered in high pitch (Ah! You are happy about it $\uparrow$ indicates the overt untruthfulness of K's assertion. As such, K's assertion of being happy about the new kings is ironic (cf. overt untruthfulness), tantamount to implicating that he does not care about the fact that the new kings were installed, and towards the end of the interaction, he displays a dissociative attitude towards the news item.

[The news item is about the newly installed chiefs in Ibadan, Oyo state, and the reaction of the indigenes of Ibadan to the exercise.]

\section{Example 3}

1. K:Bio::dun $\uparrow$

2. B: Ka::yode $\downarrow$

3. K: Bio::dun $\uparrow$

4. B: I can hear you $\uparrow$ I am not deaf

5. K: Regarding those new kings who have just been crowned $(0.1)$

6. B: Yes $\uparrow$

7. K: We are happy about it (0.2)

8. B: Ah! You are happy about it $\uparrow$

9. $\mathrm{K}$ : We have our hands in it (.)

10. B: You even have your legs in it even $\uparrow$

11. K: We have our whole body in it.

12. B: Really $\uparrow$

13. K: We even have extra support for it [like hundreds of gecko support the house

14. B:

[HehHehhehhehhehheh=

15. $\mathrm{K}:=$ Ye:::s 
16. B:HehHehHeh Well done $\uparrow=$

17. $\mathrm{K}:=$ We are re:::ally happy=

18. B: = Well done! Well done! Well done! (.1)

19. K: I am not even the one who said so.

20. B: Who said it? (.)

21. $\mathrm{K}$ : It is the indigenes of Ibadan who said it

22. B: Re:::[ally?

23. K: [Ah! How can it be me $\downarrow$ ? How is it my business $\uparrow$ ?

24. B:Okay!:: HehHehHeh (0.2)

25. K: Let me quickly read the news, please [Biodun.

26. B: [Quickly, read it, read it, let me hear.

27. (The news item is then presented)

The overt untruthfulness of K's assertion and the pretend surprise that B shows to the news sets the stage for further overt untruthfulness. $\mathrm{K}$ further asserts metaphorically that he has his hand in the installation of the kings (line 9), to which B provides a hyperbolic response that $\mathrm{K}$ even has his legs in it, and $\mathrm{K}$ moves the bar of the hyperbolic absurdity higher by saying he has his whole body in it, and has extra support even (lines 11, 13). These Quality-based figures, namely metaphor and hyperbole, are typically involved in the generation of speaker meaning, because they flout the first Quality maxim, hence indicating overt untruthfulness (Dynel 2017). Thus, the implicature generated by these figures is that K is in strong support of the installation of the new kings. B's response to K's assertions and their implicature are rather interesting: first, he contributes a hyperbolic retort (You even have your legs in it even $\uparrow$ ), he expresses surprise (line 12), and then he laughs (line 14). What these responses do is co-construct, with K's assertions, a fantasy frame where $\mathrm{K}$, a news presenter from another state is deeply involved in the installation of kings in a different state. This joint fantasising of pretend assertions and surprise are co-constructed for the amusement of the listeners to the radio programme.

Furthermore, in lines 16 and 18, B greets $\mathrm{K}$ for having done well. However, the specific utterance (e kare) used to express this greeting is a pragmeme, a situation-bound utterance (SUB) (Kecskes 2010), "which strictly specify their own contexts" (Odebunmi 2016: 21). Kecskes (2010) specifically argues that for SUBs "the communicative meaning, the sense of the utterances, is encoded, and fixed by pragmatic conventions. Consequently, prior context encoded in them can create actual situational context" (Kecskes 2010: 2892). To this extent, $e$ kare is an SUB because it specifies its context, namely congratulatory greeting that most often carries a sarcastic undertone. Thus, when B says e kare to $\mathrm{K}$, he understands the pragmatic force or implicature, namely 'you cannot be serious about what you just said'. And just after a brief pause (line 18), K declares that he was not the one who made the assertions, rather they were made by indigenes of Ibadan, the city where the new kings were installed (lines 19,21), which means that the implicature attributed to $\mathrm{K}$ earlier is now attributable to the indigenes of Ibadan. Furthermore, $\mathrm{K}$ displays a dissociative attitude towards the assertions he attributed to himself earlier in the interaction (line 23). We argue here that, through this dissociative attitude, the presenters express a dis-affiliative opinion towards the news item.

\section{Pragmatic act, humour types, and the GSP of $L I A B K$}

In this section, we argue that, even if Dynel's (2017) neo-Gricean concept of untruthfulness is able to account for the internal pragmatic mechanism of categories of humour analysed above, it is incapable of handling the interactional mechanism that organises the performance of the 
conversational humour. In other words, the internally diversified concept of untruthfulness pertains strictly to the subjective belief of the speaker vis-à-vis what is said or implicated, it does not speak to the intersubjective, co-construction of interactional phenomena, in the case of the current study conversational humour. The latter is the purview of pragmatic act (Culpeper \& Haugh 2014). Furthermore, the question of the social goals of the presenters for engaging in conversational humour cannot be explained through concept of untruthfulness (Dynel 2017). Thus, these two issues: 1) the interactional dimension of the humour types and 2) the social goals of the presenters or the pragmatic function of the humour types are analysed through pragmatic acts theory. Recall that in Section 2.3 we indicated three fundamental assumptions of pragmatic acts: 1) pragmatic acts develop both incrementally and sequentially within and across turns; 2) pragmatic acts are co-constructed by both speaker and recipients, and thus, not a product of the speaker only; and 3) pragmatic acts are constrained by and constitutive of the broader activity types (or communicative genres) that frame them.

In light of these assumptions, the humour types identified, namely song-as-humour, absurdity, joint fantasising, speaker-meaning telic humour, are all instances of the pragmatic act of doing conversational humour as incrementality, sequentiality and genre-based expectations and affordances are germane to understanding how and why they emerge in $L I A B K$. Take absurdity and joint fantasising as cases in point (cf. examples 1-2 reproduced here as example 4). The pragmatic act of doing humour developed both incrementally and sequentially within and across turns in example 4. Incrementally in the sense that Biodun adjusts or modifies his talk "in light of how the progressive uttering of units of talk is received" (Culpeper \& Haugh 2014: 185) by Kayode and vice visa. For instance, in example 4 the presenters adjust their talks in light of each other's talk. Turns 1-15 has Biodun teasing Kayode (turns 2, 7, 10, 12) with Kayode contributing mostly laughter to the interaction. However, the table turns between 16 and 22, when Kayode adjusts his contribution in light of Biodun's teasing act, and begins to tease Biodun about his late mother-in-law. The incremental adjustments Kayode's turns relative to Biodun's teasing turns, and then, of Biodun's ones relative to Kayode's is the process through which the pragmatic act of doing conversational humour is performed. Essentially, the alternation of adjusted or modified talks between Biodun and Kayode reveals the progression of the interactional humour and the fact that the presenters received each other's talk as humour and as the basis to contribute more humour.

\section{Example 4}

1. K: The mother of the child $\uparrow$

2. B: No:: I won't greet the mother. hhh $£$ Father of the child

3. K: [Congra-

4. B: $£[$ Congratulation $(0.2)$

5. B: HehHeh

6. (the presenters mimic instrumental sounds)

7. B : Father of the child, I greet you $\downarrow$ (.)

8. $\mathrm{K}:=$ Congratulations $\uparrow$

9. $\mathrm{B}:=$ Congratulations $\uparrow$

10. B: $\rightarrow £$ Kayode’s hands are in the water "o". Congrat[ulations $\uparrow(0.2)$

11. $\mathrm{K}: \rightarrow \quad$ [How will I read out the news then? $(0.2)$

12. B: $\rightarrow$.hhh £Oku owolomi [o Congratulations (Cultural greeting for parents of newborn. It literally means well done for having your hands in the water)

13. K: [HehHehHehHeh

14. B: HehHehHehHeh[HehHEh 


\section{B: HehHehHehHeh[HehHEh}

16. $\mathrm{K}$ : [Boidun is someone who can get one into trouble=

17. $\mathrm{B}:=$ HehHehHehHehHeh=

18. K: Congr(h)atulation=

19. B: = HehHehHehHehHeh

20. K: $£$ His in-law died, and we didn't sing o Congra(h)tulation $=$

21. B: = Hehhehheh That's a dead body, it has gone to rest

22. K: B Hehhehhehheh

23. $\mathrm{B}:=$ This is a newborn baby who has just arrived $o$. Congratulations. Who knows if it is my wife's mother who re-incarnated in your home $o$. Congratulations.

24. K: Your wife's mother was very dark. Congratulations.

25. B: Is your baby light-skinned?

26. K: The child we have just given birth to is an albino [Congratulations Hehhehhehheh.

27. B: ALBINO $\uparrow$ I doubt if you own the child [then $o$

28. K: It doesn't concern you $o$, there is albino in our [lineage

Additionally, turns 20-28 illustrate sequentiality in pragmatic acts. In turn $20, \mathrm{~K}$ refers to the death of B's mother-in-law, which then constrains subsequent turns in terms of subject matter and degree of the jocular mockery that turn 20 introduces. While K's joke references the death of B's mother-in-law, B's joke in return borders on the possibility of K's wife being unfaithful to him. Both jokes are sequentially equivalent in relation to the degree of absurdity. Furthermore, sequentiality plays a central role in the understanding of turn 12 , which is a cultural greeting to the parents of a new baby. Overall, the trajectory of the conversational humour in example 4 emerges as a joint, co-constructed effort between the presenters, and not strictly based on the mental state of the speakers vis-à-vis what is said or implicated.

Moreover, it is important to note that the presenters' pragmatic act of conversational humour is constrained by the GSP of the discourse. In other words, the specific stage of the interaction provides specific affordances to the speakers, and the pragmatic acts performed within the stages are realisations of specific pragmeme. So, what is the pragmeme that is executed within the Opening, Pre-news Presentation, and Closing stages of LIABK? It is entertainment, which then affords the presenters the opportunity to perform the pragmatic acts of conversational humour. In other words, because the social goal or expectation for the presenters at these stages of the interaction is to entertain the listeners, it cues the speakers to sing, tell non-news stories, tell jokes, tease each other, and engage in absurdity and joint fantasising, so as to keep listeners tuned in. Additionally, this act of providing entertainment in a news programme (a genre traditionally marked for information dissemination) through humour has a remote agenda, namely to attract more listeners to the radio programme (cf. Ojebuyi \& Ojebode 2012). In the competitive world of mass communication, the station with creative presenters is more likely to have a large listenership and the eventual benefit of high patronage in terms of placement of advertisements. Thus, the larger the audience of the radio programme, the higher the possibility of patronage. Holton \& Lewis (2011: paragraph 3) make an interesting argument when they evince that

[w]ith so much information available through so many outlets, today's news and information consumers may indeed want more than just news [...] they may want $[\ldots]$ to feel part of the news and information ecology, having a more personal connection with news messages and those journalists behind them.

The fellow-feeling or connection with the journalists in $L I A B K$ is cultivated through humour. For instance, during the joint fantasising session co-constructed by the presenters 
(lines 15-28), where they talk about personal issues such as the birth of a new baby and the death of an in-law, and where they jocularly mock each other, can be a point of connection between them and the listeners, precisely because the listeners can easily relate to the issues of birth and death and language play. Thus, the pragmatic act transforms the interaction from the formal context of information presentation to the informal context of conversation and conviviality akin to newspaper stand interactions, where discussions oscillate between newspaper headlines and personal issues to jocularities.

Speaker-meaning-telic humour, on the other hand, keys in with the pragmeme of offering opinion, which is contrary to professional journalistic norm that emphasises unbiased information, objective, and truthful presentation of news items (Kovach \& Rosenstiel 2010; Holton \& Lewis 2011). However, through the pragmatic act of creatively lacing the presentation of news items with humour, the presenters blend two disparate genres, namely everyday spontaneous conversation (which is very conducive to humour) and the journalistic genre (which is strictly speaking suspicious of humour), to create a hybrid genre that accommodates both humour and journalistic discourse. This hybrid genre is secondary gatekeeping (Ojebuyi \& Ojebode 2012). Arguably, the $L I A B K$ radio news programme is one of the most listened to in the South-western states of Ekiti and Ondo, Nigeria. In addition, similar radio news programmes that adopt the creative use of humour during news presentation are emerging in other states across South-western Nigeria (cf. Ojebuyi \& Ojebode 2012 for radio stations in Oyo State). In a nutshell, through the pragmeme of entertainment performed through autotelic humour and the pragmeme of creativity, the presenters of $L I A B K$ indirectly pursue the goal of gathering a large listenership, and that of stretching and bending the traditional norms of journalism as well as creating a hybrid genre that accommodates humour and news presentation.

\section{Conclusion}

In this paper, we investigated the genre status of $L I A B K$, which is an instance of secondary gatekeeping in Nigerian broadcast media, and analysed instances of conversational humour therein. We argue that the stages of the programme, namely Opening, Closing, and Pre-news Presentation, as revealed through its GSP, cue the radio presenters to engage in conversational humour, as the genre-based expectation for these stages is to provide entertainment for the listeners. The stage of News Presentation strictly requires the presenters to read the news, which is consistent with journalistic expectations. Thus, two disparate genre-based expectations underlie $L I A B K$, hence its characterisation as a hybrid genre that straddles spontaneous conversational style (very conducive to humour) and journalistic discourse.

Dynel's (2017) theory of untruthfulness reveals the internal pragmatic mechanism of humour, namely that it consists mostly of saying what one does not believe to be true. Following this principle, we analysed instances of autotelic humour (song-as-humour, absurdity, joint fantasising) and speaker-meaning-telic humour. While song-as-humour is fuzzy with respect to autotelicity, absurdity and joint fantasising are clear cases of autotelic humour. The interactional organisation of the humour types in terms of incrementality, sequentiality, co-construction, and pragmemic functions are analysed through pragmatic act theory. Our analysis shows that the trajectory of the conversational humour in the data emerges as a joint, co-constructed effort between the presenters, and not strictly based on the mental state of an individual speaker vis-à-vis what is said or implicated. Furthermore, the pragmeme of entertainment and offering of opinion by the news presenters constitute the 
affordances or genre-based expectations that constrain the social activities that constitute $L I A B K$.

The study contributes to the scholarship on secondary gatekeeping in Nigeria broadcast media, conversational humour, and pragmatics. With respect to secondary gatekeeping, the study indicates that it is a hybrid genre conducive to both humour and information dissemination. In other words, it has the capacity to provide infotainment and, thus, has a high market value. For conversational humour, we argue that a framework that takes into cognizance the internal pragmatic mechanisms underlying the humour types, the interactional mechanisms organising them as well as the contextual affordances and expectation constraining them, would provide a robust explanation of the phenomenon. By coalescing disparate traditions in pragmatics such as the neo-Gricean, philosophic, and the social strands respectively, we conclude that an effective pragmatics of humour may need to combine insights from these perspectives to tease out, more fruitfully and comprehensively, the mechanisms of conversational humour in a given dataset. Future studies may consider the participation configuration or the pragmatics of voice in $L I A B K$ radio news programme.

\section{Notes}

${ }^{1}$ This paper argues that speaker meaning and pragmatic acting are not the same. Best still, speaker meaning in the sense theorised by Gricean and Neo-Gricean scholars is the exclusive preserve of the speaker, in terms of what s/he says or implicates. Culpeper \& Haugh (2014: 86) capture this point better as they evince that

following Grice, pragmatic meaning representations are generally understood as the speaker's reflexively intended mental state. In other words, a speaker's belief, thought, desire, attitude, intention and so on, which is intended by the speaker to be recognised by the hearer as intended.

Secondly, speaker meaning as pursued by Dynel (2017) is largely theoretical and underpinned by a philosophic tradition. Pragmatic acting, on the other hand, transcends the intention of the speaker and factors into the process of meaning construction the societal environment within which both the speaker, and the hearer find their affordances. Thus, the speaker may have his/her intended meaning, but must consider how his/her environment provides for the articulation of such intention. Essentially, it is this environmental, societal constrains, and affordances that distinguish speaker meaning, in Grice's sense, from pragmatic acting.

\section{Transcription conventions}

[ ] indicating overlap

... omission

(0.2) indicating elapsed time in tenths of seconds

(.) indicating a brief pause

( ), indicating inaudibility

$<>$ talk said more slowly than surrounding

$><$ talk said more quickly than surrounding talk

@ laughter

::: prolongation

$\uparrow \downarrow$ high or low pitch

(( )) transcriber's descriptions 
WORD (upper case) loud volume relative to the surrounding talk

${ }^{\circ}$ word ${ }^{\circ}$ word/utterance indicating that the sounds are softer than the surrounding talk

$=$ no break or gap

- - indicating a short or untimed interval without talk

\section{References}

Capone, A. (2005). 'Pragmemes: a study with reference to English and Italian'. Journal of Pragmatics 37(9), pp. 1355-1371.

Capone, A. (2016). 'Introducing the notion of the pragmeme', in Allan, K., Capone, A., \& Kecskes, I. (eds.), Pragmemes and the theories of language use, Cham, Switzerland: Springer International Publishing, pp. xv-xxiv.

Chovanec, J. (2012). 'Conversational humour and joint fantasizing in online journalism', in Chovanec, J. \& Ermida, I. (eds.), Language and Humour in the Media, Newcastle Upon Tyne: Cambridge Scholars Publishing, pp. 131-169.

Chovanec, J. (2017). 'Interactional humour and spontaneity in TV documentaries'. Lingua 197, pp. 34-49.

Clark, H. H \& Van Der Wege, M. M. (2001). 'Imagination in discourse', in Schiffrin, D., Tannen, D. \& Hamilton, H.H. (eds.), The Handbook of Discourse Analysis, Malden, MA: Blackwell, pp. 772-86.

Culpeper, J. \& Haugh, M. (2014). Pragmatics and the English language. UK: Palgrave.

Dynel, M. (2017). 'But seriously: On conversational humour and (un)truthfulness'. Lingua 197, pp. 82-102.

Dynel, M. (2011). 'Joker in the pack: towards determining the status of humorous framing in conversations', in Dynel, M. (ed.), The Pragmatics of Humour Across Discourse Domains, Amsterdam/Philadelphia: John Benjamins, pp. 217-241.

Glenn, P. (2003). Laughter in Interaction. Cambridge: Cambridge University Press.

Goodwin, M. H. \& Goodwin, C. (1987). 'Children's arguing', in Philips, S.U., Steele, S. \& Tanz, C. (eds.), Language, Gender \& Sex in Comparative Perspective, Cambridge: Cambridge University Press, pp. 200-48.

Grice, H.P. (1989). Studies in the Way of Words. Cambridge, MA: Harvard University Press.

Halliday, M. A. K. and Hasan R. (1985). Language, Context and Text: Aspects of Language in a Social Semiotic Perspective. Oxford: Oxford University Press.

Hasan, R. (2014). 'Towards a paradigmatic description of context: systems, metafunctions, and semantics'. Functional Linguistics 1(9), pp. 1-54.

Haugh, M. (2010). 'Jocular mockery, (dis)affiliation, and face'. Journal of Pragmatics 42, pp. 2106-2119.

Holt, E. (2016). 'Laughter at last: playfulness and laughter in interaction'. Journal of Pragmatics 100, pp. 89-102.

Holton, A. E. \& Lewis, S. C. (2011) 'Journalists, social media, and the use of humour on Twitter'. The Electronic Journal of Communication 21(1\&2). [Online] http://www.cios.org/EJCPUBLIC/021/1/021121.html. [Accessed October, 2017.]

Inya, O. (2012). 'Generic structure potential of Christian apologetics'. Linguistik Online 55, pp. 75-87.

Jefferson, G. (2004). 'Glossary of transcription symbols with an introduction', in Lerner, G.H (ed.), Conversation Analysis: Studies from the First Generation, Amsterdam/Philadelphia: John Benjamins, pp. 13-31.

Kecskes, I. (2010). 'Situation-bound utterances as pragmatic acts'. Journal of Pragmatics 42(1), pp. 2889-97. 
Kotthoff, H. (1999). 'Coherent keying in conversational humour: contextualising joint fictionalisation', in Bublitz, W., Lenk, U. \& Ventola, E. (eds.), Coherence in Spoken and Written Discourse, Amsterdam: John Benjamins, , pp. 125-150.

Kovach, B. \& Rosenstiel, T. (2010). Blur: How to Know What's True in the Age of Information Overload. New York: Bloomsbury.

Lockyer, S. \& Pickering, M. (2008). 'You must be joking: the sociological critique of humour and comic media'. Sociol. Compass 2 (3), pp. 808-820.

Mey, J. L. (2001). Pragmatics. An Introduction. Malden: Blackwell.

Mey, J. L. (2009). 'Pragmatic act', in Mey, J. L. (ed.), Concise Encyclopaedia of Pragmatics, Amsterdam/New York: Elsevier, pp. 748-756.

Mey, J. L. (2016). 'Why we need the pragmeme, or: speech acting and its peripeties', in Allan, K., Capone, A., \& Kecskes, I. (eds.), Pragmemes and the Theories of Language Use, Cham, Switzerland: Springer International Publishing, pp. 133-140.

Norrick, N. (1993). Conversational Joking: Humour in Everyday Talk. Bloomington: Indiana University Press.

Odebunmi, A. (2016). 'Language, context and society: a theoretical anchorage', in Odebunmi, A., \& Ayoola, K. A. (eds.), Language, Context and Society, Ile-Ife, Nigeria: Obafemi Awolowo University Press, pp. 3-37.

Ojebuyi, B. R. \& Ojebode, A. (2012). 'Rhetorical strategies in secondary news presentation by radio stations in Oyo State, Nigeria'. Ibadan Journal of English Studies 8, pp. 62-74.

Raskin, V. (1985). Semantic Mechanisms of Humour. Dordrecht: D. Reidel Publishing Company.

Raskin, V. \& Attardo, S. (1994). 'Non-literalness and non-bona-fide in language: an approach to formal and computational treatments of humour'. Pragmatics \& Cognition 2, pp. 31-69.

Sacks, H. (1992). Lectures on Conversation, vols. I and II. Edited by Jefferson, G. Oxford: Blackwell.

Shaw, C., Hepburn, A., \& Potter, J. (2013). 'Having the last laugh: on post-completion laughter particles', in Glenn, Ph.. \& Holt, E. (eds.) Studies of Laughter in Interaction, London: Bloomsbury Academic, pp. 91-106.

Stallone, L. \& Haugh, M. (2017). 'Joint fantasising as relational practice in Brazilian Portuguese interactions'. Language \& Communication 55, pp. 10-23.

Singer J. (2014). 'User-generated visibility: secondary gatekeeping in a shared media space'. New Media \& Society 16 (1), pp. 55-73.

Vincent Marrelli, J. (1994). 'On non-serious talk: some cross-cultural remarks on the un/importance of (not) being earnest', in Parret, H. (ed.), Pretending to Communicate, Berlin: De Gruyter, pp. 253-275.

Wilson, D. \& Sperber, D. (2000). 'Truthfulness and relevance'. UCL Working Paper in Linguistics 12, pp. 215-254. 